\title{
Ocriplasmin: who is the best candidate?
}

This article was published in the following Dove Press journal:

Clinical Ophthalmology

17 March 2016

Number of times this article has been viewed

\section{Claudia M Prospero Ponce William Stevenson \\ Rachel Gelman \\ Daniel R Agarwal \\ John B Christoforidis}

Retina Division, Department of Ophthalmology, University of Arizona Medical Center, Tucson, AZ, USA
Correspondence: John B Christoforidis Retina Division, Department of Ophthalmology, University of Arizona Medical Center, 655 North Alvernon Way, Suite 108, Tucson, AZ 857II, USA Tel + I 520 32I 3677

Email jchristoforidis@eyes.arizona.edu
Abstract: Enzymatic vitreolysis is currently the focus of attention around the world for treating vitreomacular traction and full-thickness macular hole. Induction of posterior vitreous detachment is an active area of developmental clinical and basic research. Despite exerting an incompletely elucidated physiological effect, ocriplasmin (also known as microplasmin) has been recognized to serve as a well-tolerated intravitreal injection for the treatment of vitreomacular traction and full-thickness macular hole. There are several unexplored areas of intervention where enzymatic vitreolysis could potentially be used (ie, diabetic macular edema). Recent promising studies have included combinations of enzymatic approaches and new synthetic molecules that induce complete posterior vitreous detachment as well as antiangiogenesis. Although no guidelines have been proposed for the use of ocriplasmin, this review attempts to aid physicians in answering the most important question, "Who is the best candidate?"

Keywords: vitreomacular traction, macular hole, enzymatic vitreolysis, ocriplasmin-best candidate, diabetic macular edema, future management

\section{Introduction}

There are a variety of disorders of the vitreoretinal interface. Over the past 10 years, special attention has been paid to vitreomacular traction (VMT), the treatment and management of which have been constantly modified following the increasing understanding of the vitreous' molecular and anatomical behaviours at the vitreoretinal interface.

In this review, we intend to guide the reader through the beginnings of enzymatic vitreolysis, as well as controversies and recent discoveries related to ocriplasmin, with a review of the anatomy for further understanding of this review.

\section{Vitreous anatomy and molecular structure}

The vitreous humor is composed of mostly water $(\sim 98 \%) .{ }^{1,2}$ The framework that supports the vitreous humor is made of collagen II, IV, V/XI, VI, and IX fibrils, ${ }^{1,3}$ as well as hyaluronic acid (hyaloid meaning glassy), which is negatively charged and hydrophilic. Hyaluronic acid is embedded in between the "scaffold-like" configuration of the collagen fibrils, thus building up the structure. ${ }^{4}$

At birth, the vitreous humor is attached only at the ora serrata; later, it migrates to form an annular ring straddling the ora..$^{5}$ The vitreous humor expands to the remaining portions of the retina aided by production of new collagen by retinal cells. This collagen either breaks into the inner limiting membrane (ILM) to attach to the cortical vitreous collagen or remains in the cellular zone of the ILM. ${ }^{5}$

The outer vitreous is called the vitreous cortex and is very different from the inner vitreous. The vitreous cortex is mainly composed of types II, IX, and V/XI hybrid collagen. Although the vitreous cortex runs along the ILM, these structures differ significantly in composition. The ILM is mainly composed of collagen IV and is 
derived from the same embryologic component as Bruch's membrane. ${ }^{4,6}$ The vitreous is divided into anterior cortex and posterior cortex. The anterior attachment of the vitreous is firm (vitreous base and ora serrata) while the attachment of the posterior vitreous, both to the optic nerve $(\mathrm{ON})$ and to the macula, is weaker. ${ }^{2}$ Strong zones of attachment are found in places where the ILM is thin, eg, in lattice degeneration, retinal tufts, enclosed ora bays, following retinal vessels, and foveola. ${ }^{4,7}$ This may explain why after an incomplete posterior vitreous detachment (PVD), the tractional effect is generally persistent in zones of $\leq 500 \mu \mathrm{m}$ of vitreofoveolar adhesion. $^{8,9}$ The presence of liquefaction without dehiscence of the vitreous, "anomalous PVD", may predispose to persistent attachment of vitreous, causing vitreoschisis, a phenomenon that splits the posterior vitreous cortex and provides several types of traction (centripetal, centrifugal, and tangential). ${ }^{4,7}$ It is precisely this minimal zone of traction that is related to lamellar, micro, or full-thickness macular holes (FTMH). ${ }^{8}$

With time, the vitreous loses its firmness in a process known as age-related liquefaction. ${ }^{1}$ Several molecular and histopathological approaches have been undertaken to further explain this phenomenon. For instance, it has been shown that adults at the age of 40 years predominantly have liquid vitreous vs gel vitreous, in comparison to children, who have only $20 \%$ of vitreous in the form of liquid. ${ }^{1,10}$ This liquefactive change is believed to be secondary to an uneven collapse of collagen fibrils mainly in the central vitreous. ${ }^{11}$ One of the most studied processes is that of progressive degeneration of collagen IX. The half-life for collagen IX is 11 years, and it has been proven that the loss of these fibrils with time allows other collagen fibrils, such as collagen II that has a high fusion power, ${ }^{1}$ to aggregate, changing the vitreous anatomy.

Innovative methods of visualizing the vitreous include diffusion-weighted imaging - a form of magnetic resonance imaging - which can be used to track the movement of water protons. Meral and Birgili ${ }^{12}$ demonstrated that diffusion tends to increase with age, due to a decrease in cellularity and an increase in potential spaces in which water molecules can move.

As part of the aging process, PVD may occur. PVD refers to detachment of the posterior vitreous, which occurs in $>27 \%$ of people with increased age and in up to $60 \%$ of patients $>60$ years of age. ${ }^{13,14}$ Both vitreous liquefaction and vitreoretinal attachment weakening are present in PVD. As already mentioned, PVD may be complete or incomplete. In a complete detachment, there is no residual adherence to the $\mathrm{ON}$ or retina, and the posterior vitreous simply moves forward to occupy the center of the vitreous cavity. ${ }^{1,14}$ Because there is no remaining vitreous contact with the retina, PVD has been shown to protect against some vitreoretinal pathologies, such as proliferative diabetic retinopathy. ${ }^{15}$

\section{VMT syndrome}

When vitreous development is abnormal, it leads to vitreoretinal pathologies that may affect patients' vision negatively.

Approximately 3 decades ago, ophthalmologists were able to clinically identify three similar vitreoretinal disease conditions $^{16}$ : epiretinal membrane (ERM), idiopathic macular hole, and impending macular hole. ${ }^{15,16}$ These conditions were clinically described and classified by Gass in $1988,{ }^{17}$ but only after the application of optical coherence tomography (OCT) did the classification become more objective. Even with a clear slit-lamp view, fluid-filled pockets can sometimes be misinterpreted as "complete detachment". ${ }^{18}$

Macular pucker, macular hole (lamellar, full-thickness), and VMT share a common etiology in PVD with persistent vitreomacular adhesion (VMA). ${ }^{4}$ Macular pucker can occur when traction is directed inward, and macular hole can occur when traction is directed outward. ${ }^{6,19}$ Idiopathic macular pucker has been described as a "nonvascularized ERM covering and/or distorting macula" without any history of surgery, lattice degeneration, or inflammation. ${ }^{20,21}$ Impending macular hole is described as a yellowish deep ring in the macula related to mild visual loss. ${ }^{17,22}$

Smiddy et $\mathrm{al}^{20}$ studied vitreomacular diseases and their histopathology. All idiopathic macular pucker cases $(n=101)$ were found to exhibit previous PVD, although these PVDs were not further specified as being complete or incomplete. Histologically, the predominant cell type in macular pucker was the retinal pigment epithelium (RPE) cell, with some cases involving astrocytes and fibrocytes. Additionally, all of the VMT cases involved a partial PVD with persistent attachment to the macula and ON, with histology showing fibrous astrocytes to be the predominant cell type. In the case of impending macular hole, collagen fibrils were predominant in all cases, with some tissues involving fibrous astrocytes, lymphocytes, or macrophages. ${ }^{20}$ More recently, Schumann et $\mathrm{al}^{23}$ retrieved ILM specimens from patients who had vitrectomies with or without prior ocriplasmin injection. Immunohistochemistry revealed that the predominant cells in FMTH and VMT were glial cells and myofibroblasts, respectively.

Incomplete PVD may appear if liquefaction and dehiscence are not balanced, causing vitreopapillary traction as well as optic disk and retinal neovascularization. ${ }^{4}$ VMT often extends to up to three disk diameters in the posterior retina ${ }^{24,25}$ 
Table I IVTS study classification

\begin{tabular}{lll}
\hline VMA & VMT & Full-thickness macular hole \\
\hline Size & Focal $(\leq 1,500 \mu \mathrm{m})$ or broad & Small $(\leq 250 \mu \mathrm{m})$ \\
$\begin{array}{l}\text { Focal }(\leq 1,500 \mu \mathrm{m}) \text { or broad } \\
(>1,500 \mu \mathrm{m})\end{array}$ & $(>1,500 \mu \mathrm{m})$ & Medium $(>250-\leq 400 \mu \mathrm{m})$ \\
$\begin{array}{l}\text { Characteristic } \\
\text { Isolated* or concurrent }\end{array}$ & Large $(>400 \mu \mathrm{m})$ \\
& Isolated or concurrent & Status of vitreous: with or without VMT \\
\hline
\end{tabular}

Note: *Without other associated macular abnormalities.

Abbreviations: IVTS, International Vitreomacular Traction Study group; VMA, vitreomacular adhesion; VMT, vitreomacular traction.

and can therefore affect vision outcomes. Symptomatic VMT clinically presents as metamorphopsia, micropsia, photopsia, or decreased vision ${ }^{26,27}$ and is seen as a peripheral separation with full-thickness attachment of the vitreous cortex, which applies traction on the macula in an oblique or axial force. A V-shaped pattern of incomplete PVD may have a better visual acuity (VA) prognosis when compared to a J-shaped pattern. ${ }^{27-29}$

Interestingly, similar abnormal retinal traction is seen in collagen deficiency syndromes (Stickler, Ehlers-Danlos, and Marfan syndromes) wherein there is predominant liquefaction, persistent retinal attachment, and resulting retinal detachment and/or tears..$^{30,31}$

According to the International Vitreomacular Traction Study Group, ${ }^{32}$ VMT is characterized by anomalous PVD with distortion of the fovea, including but not limited to the following: subretinal fluid (SRF) collection, pseudocysts, cystoid macular edema, and schisis. Classification is shown in Table 1.

Although some patients may develop spontaneous complete PVD with improvement of foveal structure and VA, ${ }^{33}$ most of the patients do not show resolution of symptoms without intervention.

\section{Surgery and vitreoretinal interface}

Vitrectomy has been a promising solution for VMA, including macular pucker and hole, as well as VMT. Vitrectomy was initially used for ERM removal with VA improvement in $\sim 80 \%$ of patients. ${ }^{20,21,34,35}$ Cataract and ERM formation limited the VA outcome. ${ }^{36}$

Surgical management of macular pucker includes peripheral and central core vitrectomy with ILM membrane removal to prevent recurrence. ${ }^{37}$ Although there are no true guidelines for surgical intervention, indications for surgery include photoreceptor damage demonstrated on OCT, metamorphopsia, or progressive vision loss. The normal structure of photoreceptor is assessed using OCT by looking at the boundary between the inner and outer segments, which some have defined as the ellipsoid zone, ${ }^{37}$ and the interdigitation zone, which is the communication area between inner segments and RPE. ${ }^{37-43}$

Intact layer of photoreceptors, good baseline VA, and short-term symptoms are prognostic factors for good surgery outcomes. ${ }^{18,37}$ However, surgery may change the retinal anatomy even when there is evidence of normal anatomy prior to surgery. Interestingly, foveal architecture is less correlated with good VA because previous data have demonstrated that vision recovery after surgery may occur despite an abnormal foveal contour.

Similar indications are used to guide intervention for pseudoholes and macular holes, and intervention is often combined with a mechanical type of repositioning of the retinal layers, such as gas tamponade. ${ }^{37}$ For macular holes, the main indicator of prognosis is the base diameter. A measurement of $<500 \mu \mathrm{m}$ is an indicator of high success rate, ${ }^{44,45}$ with ILM removal usually indicated for better outcome. ${ }^{45}$ An exception is lamellar macular hole, because visual deterioration was found to be related to the amount of VMT, macular edema, hole base diameter, and - possibly decreased foveal thickness. ${ }^{6,19,46,47}$

It is debatable if mechanical gas tamponade is useful as a treatment for VMT. However, recent reports showed promising results using expansile sulfur hexafluoride (SF6) gas injection for the treatment of symptomatic VMT syndrome. Day et $\mathrm{al}^{48}$ reported VMT release in five patients and resolution of macular hole in two patients after injection of $0.3 \mathrm{~mL}$ of $100 \% \mathrm{SF} 6$ gas. Rodrigues et al reported that intravitreal injection of expansile perfluoropropane (C3F8) for the treatment of VMT achieved $40 \%$ release rate 1 month after injection (five out of seven patients). ${ }^{49}$

VMT surgery, on the other hand, has a more well-defined indication. Per Figueroa and Contreras, ${ }^{37}$ surgery should be performed not only if metamorphopsia is present, but also when patients have VA $\leq 20 / 40$.

Additionally, when retinal traction is present, it can evolve either to a lamellar macular hole or FTMH, ${ }^{29,32}$ or to other sight-threatening complications such as diabetic retinopathy 
(DR), ${ }^{15}$ macular edema and cystic changes, ${ }^{20,24,50,51}$ macular detachment, ${ }^{52}$ retinal vein occlusion, ${ }^{51,53-55}$ and even agerelated macular degeneration (AMD). ${ }^{55-58}$ Therefore, when present on OCT, retinal traction should be relieved by the surgical or enzymatic approach.

\section{Enzymatic vitreolysis}

During the past 2 decades, induction of PVD has been attempted with the use of molecular (enzymatic) rather than mechanical (surgical) means.

Enzymatic vitreolysis has several advantages over surgical intervention because the former is 1) broader, reaching both the posterior pole and the periphery, 2) less traumatic for the macula and the eye in general, 3) prophylactic in retinal pathologies that include fibrocellular or fibrovascular proliferation (except for proliferative vitreoretinopathy where RPE cells proliferate), 4) protective against retinal hypoxia, ${ }^{59-64}$ ERM formation, ${ }^{36}$ and nerve fiber layer defects occasionally seen after ILM surgery, ${ }^{62}$ and 5) with less cataract formation. ${ }^{62}$

\section{First enzymatic agents}

The effectiveness of pharmacologic vitreolysis is directly related to the successful balance between liquefaction and dehiscence. ${ }^{4}$ Pharmacologic agents previously used for this purpose included hyaluronidase, chondroitinase, dispase, collagenase, plasmin, tissue plasmininogen activator (tPA), and microplasmin/ocriplasmin, ${ }^{4,54}$ among others.

Hyaluronidase has been used as an enzymatic agent to induce vitreolysis. ${ }^{4,65}$ It has been found to be dose dependent and effective in the eyes of rabbits, ${ }^{65,66}$ rats, ${ }^{67}$ pigs, ${ }^{68}$ cows, ${ }^{69}$ and humans. ${ }^{65,70}$ Even when liquefaction was the consistently found main effect, it was primarily aimed for vitreous hemorrhage management. ${ }^{70}$

Chondroitinase has been used for vitreolysis in some animal models such as pigs, ${ }^{71}$ bovines, ${ }^{69}$ and primates, ${ }^{72}$ with no significant effect. Chondroitinase has shown some vitreous fiber detachment only in some human cadaver eyes. ${ }^{72}$ To date, this has not been investigated any further.

Dispase is an enzyme that acts against collagen, mainly type IV. ${ }^{73}$ Dispase has been also applied to human and pig eyes to induce vitreolysis, and although it is somewhat effective, it has been shown to cause retinal toxicity. ${ }^{74}$

Urokinase has been used in a rabbit model along with SF6 to induce vitreolysis and has been effective in $75 \%$ of the eyes, ${ }^{75}$ but it has not been used as a single agent. Urokinase shows no retinal toxicity in rabbit eyes. ${ }^{76}$

Bacterial collagenase activity has been shown to produce effective vitreolysis in a different set of animal models ${ }^{77,78}$ and to reduce the molecular weight of collagen. ${ }^{79}$ In a pilot human study, ${ }^{80}$ it has been suggested to be an aid in the removal of fibrotic membranes in some patients intraoperatively; however, the results do not have statistical significance and are inconsistent. In a subsequent study, ${ }^{81}$ collagenase activity in the vitreous has been widely proven to be toxic to the retina.

Intravitreal tPA, which converts plasminogen into plasmin in vivo, has been effective in facilitating vitrectomy when given prior to surgery and after cryopexy, ${ }^{82,83}$ as well as inducing PVD even without vitrectomy. ${ }^{84,85}$ However, variable effects have been reported because they depend on the amount of endogenous plasminogen present in the vitreous. ${ }^{54,83}$ It has been hypothesized that plasminogen is increased in conditions where the blood retinal barrier has been violated, such as after cryopexy, ${ }^{83} \mathrm{DR},{ }^{86}$ retinal vein occlusion, ${ }^{85}$ etc. Retinal toxicity has also been reported. ${ }^{87-89}$

Plasmin is a $88 \mathrm{kDa}$ molecule $\mathrm{k}^{62,90}$ that has been used to induce vitreous dehiscence, for PVD induction (as an adjuvant to vitreoretinal surgery), and for macular hole treatment in pediatric and adult patients, ${ }^{91-95}$ as well as in animals. ${ }^{90,96,97}$ In order to be injected in the vitreous cavity, the plasmin has to be processed from autologous blood: the hazard involved in processing autologous plasmin is greater than the actual benefit derived. ${ }^{90,94,98-101}$ The effect of plasmin on PVD is dependent on time, also demonstrating transient retinal damage as noted by electroretinography (ERG). ${ }^{90,97}$

\section{Current enzymatic agents Ocriplasmin}

In response to the challenge of obtaining autologous plasmin, ocriplasmin (formerly called microplasmin) was created. Ocriplasmin (Jetrea; ThromboGenics NV, Leuven, Belgium) is a recombinant protein created by the Pichia pastoris expression system, with intrinsic action on collagen, fibronectin, and laminin. ${ }^{1,3}$ It is a small $27 \mathrm{kDa}$ protein that cleaves plasmin and has been shown to cause both vitreous liquefaction and PVD. ${ }^{62,63,102-104}$

Gandorfer et $\mathrm{al}^{105}$ studied the efficacy of ocriplasmin in cadaver human eyes and live cats. They studied the morphology of both groups along with a control group treated with saline solution. Complete PVD was found in all human eyes that received $125 \mu \mathrm{g}$ and in cat eyes that received $25 \mu \mathrm{g}$ intravitreally. In all cases, ILM was normal after injection. ${ }^{105}$

Human studies started $\sim 1$ decade ago. Initially, ocriplasmin was used to induce PVD and resolve VMT. VMT resolution has been reported in at least $50 \%$ of patients. ${ }^{106,107}$ 
The Microplasmin for intravitreal injection (MIVI) trial $\mathrm{I}^{108}$ studied the adequate dose needed to induce PVD prior to vitrectomy and concluded that $125 \mu \mathrm{g}$ was generally effective MIVI IIT studied the resolution of VMT after a single vs repeated ocriplasmin injections. Successful resolution of VMT was seen in $58 \%$ of patients after repeated doses of ocriplasmin $125 \mu \mathrm{g}$ up to 28 days from the previous injection. ${ }^{109}$ The MIVI TRUST group ${ }^{110}$ studied the doserelated response to ocriplasmin vs placebo in 652 eyes and found that ocriplasmin $125 \mu \mathrm{g}$ was overall more effective than placebo in the treatment of symptomatic VMT syndrome (26.5\% vs $10.1 \%$ ). Total PVD and VA improvement was noted in more ocriplasmin- than placebo (saline)-injected eyes after 28 days of injection. Release of VMT may be present even after 1 year of initial treatment. ${ }^{111,112}$ VA generally improves after VMT resolution, except for some reported exceptions. ${ }^{13,114}$ The resolution of VMA was seen mainly in the central $6 \mathrm{~mm}$ of the macula when assessed with OCT imaging. Both groups had adverse effects after the intravitreal injection, which improved later. ${ }^{115}$

Ocriplasmin was then applied for nonsurgical closure of macular hole. Initial results reported macular hole resolution as variable. ${ }^{106}$ Patients treated with ocriplasmin in the MIVI TRUST study ${ }^{110}$ had more resolution of macular hole when compared to placebo (13.4\% vs 3.7\%). Other studies had confirmed effective small and medium FTMH closure ${ }^{116}$ with ocriplasmin $\left(40.6 \%\right.$ ocriplasmin vs $10.6 \%$ control), ${ }^{117}$ and the closure of FTMH has been reported despite incomplete release of $\mathrm{VMT}^{118}$ and months after ocriplasmin injection. ${ }^{11}$

In addition to VMA resolution, foveal thickness also decreases after ocriplasmin injection. In a study of 21 patients, the average foveal thickness measured by spectral-domain OCT decreased $\sim 80 \mu \mathrm{m}$ after 4 months of injection and remained stable ${ }^{106}$

Haller et $\mathrm{al}^{110}$ studied the effect of ocriplasmin on VA in a subgroup of patients in the MIVI study, assessing whether specific end point results continued for 6 months after the initial trial. The end points were age of response, subset population with better response, etc. The analysis showed that the best outcome from start through 6 months was found in patients younger than 65 years of age and with absence of ERM, occurrence of phakic eyes, VMT $<1,500 \mu \mathrm{m}$ in diameter, and presence of FTMH of $<250 \mu \mathrm{m}$ diameter. The latter group was more likely to achieve full closure in 6 months than with FTMH $>400 \mu \mathrm{m}$ diameter $(58.3 \%$ vs $26 \%$ ) (Table 2). Although patients were followed for 6 months, the effect in younger patients is unpredictable. ${ }^{119}$ Recent work $^{120}$ has suggested that phakic, young females
Table 2 Proposed indication for ocriplasmin

\begin{tabular}{|c|c|}
\hline \multicolumn{2}{|c|}{ Best candidates for ocriplasmin injection } \\
\hline I & Phakic eyes \\
\hline 2 & Age $\leq 65$ years \\
\hline 3 & No previous surgeries \\
\hline 4 & No diabetic retinopathy \\
\hline 5 & No ERM \\
\hline 6 & $\mathrm{VMA}<\mathrm{I}, 500 \mu \mathrm{m}$ \\
\hline 7 & No macular pucker \\
\hline 8 & $\mathrm{FTMH}<250 \mu \mathrm{m}$ \\
\hline \multicolumn{2}{|c|}{ Relative Indications: } \\
\hline \multicolumn{2}{|c|}{$\mathrm{FTMH}>250 \mu \mathrm{m}$ but $<400 \mu \mathrm{m}$} \\
\hline \multicolumn{2}{|c|}{ Females } \\
\hline \multicolumn{2}{|c|}{$\begin{array}{l}\text { Specific OCT characteristics (small area of adhesion, “V-shaped” VMT } \\
\text { with wide angles) }\end{array}$} \\
\hline
\end{tabular}

Abbreviations: ERM, epiretinal membrane; FTMH, full-thickness macular hole; OCT, optical coherence tomography; VMA, vitreomacular adhesion; VMT, vitreomacular traction.

with specific OCT characteristics (small area of adhesion, V-shaped VMT with wide angles, etc) were more likely to have VMT release after ocriplasmin.

Was the "anatomic" resolution of the above clinically significant for the patients? The answer to this question was first addressed by the MIVI TRUST study. ${ }^{110}$ On average, patients spent 10 minutes answering a visual function questionnaire (VFQ-25) designed by The National Eye Institute, ${ }^{110,121,122}$ which assessed global vision rating, difficulty with near and far vision, limitations in social functioning due to vision - including dependence on others due to low vision, driving difficulties, etc. In general, patients who received ocriplasmin had improvement in best-corrected VA and quality of life.

\section{Contraindications}

Relative contraindications for ocriplasmin use include previous vitrectomy, laser/surgery 3 months earlier, intravitreal injection within 6 months, fibrocellular proliferation at the level of the ILM (including proliferative vitreoretinopathy) and ERM, ${ }^{112}$ history of rhegmatogenous detachment, myopia $>5 \mathrm{D}$ (diopters), proliferative vitreoretinopathy, FTMH $>400 \mu \mathrm{m}$, and severe peripheral retinal degeneration. In the MIVI study, ${ }^{108,109}$ patients with DR, glaucoma, uncontrolled systemic hypertension, ocular inflammation, or trauma were excluded from ocriplasmin injection. Currently, ocriplasmin is being applied in patients even with normal VA at baseline.

\section{Complications}

Some of the reported adverse effects of ocriplasmin are transient decrease in VA, which generally improves after injection, photopsias (sparkles, flashes, lines), pupillary 
abnormalities/impaired reflex, ${ }^{123}$ zonular dehiscence, ${ }^{124}$ and lens subluxation. ${ }^{125-127}$ Willekens et al ${ }^{104}$ observed a change in the cup-to-disk ratio in patients after ocriplasmin injection. There was a decrease in the cup-to-disk ratio in those with persistent VMT after injection. However, mean retinal nerve fiber layer thickness was higher in all patients regardless of injection. This may be of clinical importance in patients who are being monitored for glaucoma. This anatomical change in the ON was statistically significant; however, the power of this study was low. ${ }^{104}$

One case of sterile endophthalmitis presumed to be caused by ocriplasmin injection was found in the literature. ${ }^{128}$ A 67-year-old gentleman presented with symptoms of acute endophthalmitis within 24 hours after ocriplasmin injection; he was treated with topical steroids and cycloplegics, improving most of his symptoms. There was no tap and inject; therefore, no culture was performed.

Retinal toxicity after ocriplasmin injection has variable manifestations. ${ }^{129}$ Reported structural changes include vascular constriction, ${ }^{130}$ ellipsoid layer abnormalities (thinning, disruption, irregularity), ${ }^{107,123,130-136}$ decreased reflectivity that persisted for 2 months after treatment, ${ }^{137}$ abnormal autofluorescence, ${ }^{106,126,127,138}$ SRF collection, ${ }^{106,107,139,140}$ temporary separation of retina from $\mathrm{RPE},{ }^{138}$ macular hole enlargement, ${ }^{23,130}$ and macular detachment. ${ }^{129}$ Interestingly, central serous chorioretinopathy, a type of SRF collection, has been noted up to 17 months after injection of ocriplasmin, and despite FTMH resolution. ${ }^{141}$ In some instances, there has been resolution of post-ocriplasmin $\mathrm{SRF}^{104}$ and ellipsoid layer abnormalities $^{107,116,131-133}$ after $\sim 1$ year from injection. Most patients had a good VA outcome. ${ }^{16,131}$

Functionally, the retina has shown decreased (sometimes, flat) ERG ${ }^{107,133,137,140}$ responses, with progressive nyctalopia, ${ }^{106}$ light adaptation difficulties, ${ }^{142}$ progressive photopsias ${ }^{141}$ and visual field defects. ${ }^{137}$ Some of these complications have also been seen in animal models. ${ }^{143}$ ERG depression and abnormalities has also improved with time. ${ }^{107,133}$

Kaiser et al $^{127}$ recently published a simultaneous safety evaluation of 465 ocriplasmin vs 187 placebo eyes for VMT with or without FTMH. Some of the serious adverse effects were as follows: worsened or new FTMH (5.2\% vs 8.6\%), nonresolution of VMT (1.1\% vs $0.5 \%)$, retinal detachment $(0.4 \%$ vs $1.6 \%)$, and decreased VA $(0.6 \%$ vs $0.5 \%)$. Of note, almost half of the patients with decreased VA had complete resolution of VMT and there was only one patient in the ocriplasmin group whose etiology for decreased vision remained unknown. Safety profile evaluations had reported ocriplasmin as a "well-tolerated" treatment. ${ }^{106,126,127}$
Enlargement of FTMH ${ }^{144-146}$ has been seen after ocriplasmin injection. New-onset lamellar hole has also been reported anytime from 28 days to 7 months ${ }^{128,145,147}$ after ocriplasmin injection. Chatziralli et al ${ }^{145}$ described a new-onset lamellar hole accompanied by an interesting transient macular "remodeling", which resolved with time. It is hypothesized however, that these new-onset macular holes are simply related to intravitreal injection. ${ }^{115,145}$ The combined data of MIVI TRUST study ${ }^{115}$ revealed that macular holes were noted in both placebo and treatment groups (8.6\% vs 5.2\%). Similar data were reported for retinal detachments. ${ }^{102}$ Additionally, FMTH reopening has been seen 2 years after initial resolution of macular hole and improvement of vision from VA $20 / 100$ to VA $20 / 25{ }^{148}$ There is a subset of patients that have no response to ocriplasmin. ${ }^{149}$

The physiological effect of this enzyme in the eye tissues has been studied but has still not been fully elucidated. It has been hypothesized that it not only attacks laminin and fibrillin but may also attack other normal layers of the retina and vitreous. ${ }^{110,119,123,129}$ However, the ILM does not show specific signs of toxicity at the histology level when exposed to ocriplasmin. ${ }^{23}$

Are these adverse reactions genotype specific? Does the presence of glial cells in VMT or ERM dictate the failure of ocriplasmin treatment? ${ }^{23}$ To date, this remains an enigma. ${ }^{150}$

\section{Ocriplasmin in other pathologies}

Enzymatic vitreolysis has been shown to facilitate vitrectomy in different entities. ${ }^{103}$ In the pediatric population, a higher dose of $175 \mu \mathrm{m}$ has been used as an adjunct to vitrectomy ${ }^{151}$ in patients with variable conditions (retinopathy of prematurity, macular hole, proliferative retinopathy, etc). During surgery, it was observed that ocriplasmin induced weakening of the vitreoretinal junction. This study was merely observatory because VMT release was not confirmed with OCT or any other imaging method.

An unexplored area of enzymatic intervention is diabetic macular edema (DME) triggered by VMT..$^{50,152,153}$ Rodrigues et $\mathrm{al}^{49}$ used C3F8 gas to treat six patients with VMT related to DME and only two patients showed VMT release when assessed with OCT.

Surgical intervention to remove posterior hyaloid has been effective in decreasing the risk for DME. Macular edema may develop when unstable vitreal collagen leads to increased permeability and possible relocation of cells to the posterior hyaloid. ${ }^{152}$ Once the cells migrate, they may lead to traction in the macula. Complete vitreous liquefaction and detachment is related to less risk for DME. 
Can ocriplasmin serve as an aid to induce complete PVD and vitreous liquefaction to prevent DME? Results from MIVI-II-DME, a multicenter, double-masked, randomized, and sham-controlled trial, have already been collected. Response to different doses $(25 \mu \mathrm{g}, 75 \mu \mathrm{g}$, and $125 \mu \mathrm{g}$ ) was evaluated in selected patients. Results are not yet published. ${ }^{154}$

Another area of interest is AMD, in which vitreoretinal adhesions have been related to less response to anti-vascular endothelial growth factor therapy. Novack et al ${ }^{112}$ studied AMD patients of at least 50 years of age with active primary or recurrent choroidal neovascularization, presence of focal VMA, and with a vision 20/32 to 20/200. Results revealed that ocriplasmin has a safe profile and the majority of patients treated with ocriplasmin achieved full PVD with VMA. However, there was no VA improvement despite the use of less anti-vascular endothelial growth factor injections in the ocriplasmin group. ${ }^{112}$ Some patients had resolution of subfoveal drusenoid deposits after ocriplasmin injection and the previous diagnosis of AMD had to be modified. ${ }^{104}$ The effect of ocriplasmin in AMD has been previously studied, ${ }^{112}$ but there is no specific mention of drusen changes. This finding certainly deserves further clarification because a diagnosis of AMD is a life-changing occurrence for some patients.

Retinoschisis has also improved after ocriplasmin injection. A young 27-year-old male with X-linked retinoschisis was treated effectively with ocriplasmin. The patient in this case showed no adverse effects or decreased vision. However, resolution of the schisis cavity recurred 1 month after injection. ${ }^{155}$

\section{What is for the future?}

For ocriplasmin, there are several trials that are in progress ${ }^{156}$ to better understand the effect of ocriplasmin in real human practice.

The ORBIT trial (Ocriplasmin Research to Better Inform Treatment) ${ }^{157}$ is an observational, prospective, and multicenter study that is currently on and is expected to recruit 1,500 patients by April 2016.

The OZONE trial ${ }^{158}$ by ThromboGenics ${ }^{\circledR}$, completed in May 2015, will provide valuable information on adverse effects of ocriplasmin in the eye, as previously discussed in this review (including ellipsoid zone disruption with and without resolution, SRF collection, new-onset FTMH, impaired pupillary reflex, vascular changes, ERG changes, lens changes, quality of vision, etc). ${ }^{158}$

The OASIS trial ${ }^{159}$ will further investigate the effects of ocriplasmin injection using ERG and microperimetry results in 220 patients $\geq 18$ years of age during a 2 -year period in 25 different retina centers in the USA. Most of the subjects were reported to be female $(67.3 \%)$ and White $(89.5 \%)$. All subjects had VMA and partial PVD, with $76 \%$ presenting also with FTMH. ${ }^{159,160}$

Recent promising studies have included a combination of enzymatic approaches. Wang et $\mathrm{al}^{161}$ showed positive outcomes when plasmin was combined with hyaluronidase in rabbits. Zhi-Liang et al ${ }^{67}$ studied the effect of this combination in diabetic and nondiabetic rats, and their results indicated that the latter group achieved complete PVD 100\% of the times. The overall outcome with this combination is to both liquefy vitreous and induce PVD. Future trials to attempt this combination in humans are yet to be designed.

Additionally, a synthetic molecule ALG-1001 (Luminate $^{\circledR}$; Allegro Ophthalmics, San Juan Capistrano, CA, USA), intended to treat wet AMD and DME, showed additional induction of complete PVD in six of eleven patients, probably secondary to its blocking effect on integrin $\alpha 3 \beta 1$ receptors that bind retina with vitreous extracellular matrix. Clinical data reported a safe profile. ${ }^{162}$ ALG-1001, a Phase II, prospective, randomized, double-masked, placebocontrolled clinical trial concluded in July $2015^{163}$ and showed resolution of VMT and VMA in $65 \%$ of eyes treated with $3.2 \mathrm{mg}$, the higher dose in the study. Luminate will probably be approved by the US Food and Drug Administration for VMT treatment earlier than for wet AMD or DME because the regulatory process is less extensive. ${ }^{164}$ It is yet to be determined if the cost-benefit balance will lean favorably toward the patients.

\section{Conclusion}

Ocriplasmin remains the focus of attention around the world for treating VMT and FTMH. The efficacy of ocriplasmin in treating other entities such as DME or AMD remains unclear. It is yet to be decided by physician experts whether ocriplasmin will become the standard of care for VMT and FTMH in future ophthalmology practice. With the herein-presented review, we have provided evidence-based data that will help physicians in deciding the best candidate. In the meantime, new data are explored step by step to fully understand the behavior of this renowned enzyme.

\section{Disclosure}

The authors report no conflicts of interest in this work.

\section{References}

1. Le Goff MM, Bishop PN. Adult vitreous structure and postnatal changes. Eye. 2008;22:1214-1222. 
2. Eagle RC Jr. Eye Pathology: An Atlas and Text. 2nd ed. Philadelphia, PA: Lippincott Williams \& Wilkins; 2011.

3. Bishop PN. Structural macromolecules and supramolecular organization of the vitreous gel. Prog Retin Eye Res. 2000;19:323-344.

4. Sebag J. Anomalous posterior vitreous detachment: a unifying concept in vitreo-retinal disease. Graefes Arch Clin Exp Ophthalmol. 2004;242: 690-698.

5. Wang J, McLeod DS, Henson DB, Bishop PN. Age dependent changes in the basal retinovitreous adhesion. Invest Ophthalmol Vis Sci. 2003; 44:1793-1800.

6. Sebag J, Wang M, Nguyen D, Sadun AA. Vitreo-papillary adhesion in macular diseases. Trans Am Ophthalmol Soc. 2009;107:35-46.

7. Stalmans P, Duker JS, Kaiser PK, et al. OCT-based interpretation of the vitreomacular interface and indications for pharmacologic vitreolysis. Retina. 2013;33(10):2003-2011.

8. Johnson MW. Posterior vitreous detachment: evolution and complications of its early stages. Am J Ophthalmol. 2010;149(3):371.e-382.e.

9. Spaide RF, Wong D, Fisher Y, Goldbaum M. Correlation of vitreous attachment and foveal deformation in early macular hole states. $\mathrm{Am}$ J Ophthalmol. 2002;133:226-229.

10. Oksala A. Ultrasonic findings in the vitreous body at various ages. Albrecht Von Graefes Arch Klin Exp Ophthalmol. 1978;207(4):275.

11. Sebag J. Age-related changes in human vitreous structure. Graefes Arch Clin Exp Ophthalmol. 1987;225:89-93.

12. Meral I, Birgili Y. Diffusion changes in the vitreous humor of the eye during aging. AJNR Am J Neuroradiol. 2011;32:1563-1566.

13. Foos RY, Wheeler NC. Vitreoretinal juncture: synchysis senilis and posterior vitreous detachment. Ophthalmology. 1982;12:1502-1512.

14. Larsson L, Österlin S. Posterior vitreous detachment. A combined clinical and physicochemical study. Graefes Arch Clin Exp Ophthalmol. 1985; 223:92-95.

15. Wong H-C, Sehmi KS, McLeod D. Abortive neovascular outgrowths discovered during vitrectomy for diabetic vitreous haemorrhage. Graefes Arch Clin Exp Ophthalmol. 1989;227:237-240.

16. Machemer R. The surgical removal of epiretinal macular membranes (macular puckers) [abstract]. Klin Monatsbl Augenheilkd. 1978; 173:36-42.

17. Gass JDM. Idiopathic senile macular hole: its early stages and pathogenesis. Arch Ophthalmol. 1988;106:629-639.

18. Koerner F, Garweg F. Vitrectomy for macular pucker and vitreomacular traction syndrome. Doc Ophthalmol. 1999;97:245-254.

19. Wang MY, Nguyen D, Hindoyan N, Sadun AA, Sebag J. Vitreopapillary adhesion in macular hole and macular pucker. Retina. 2009;29: 644-650.

20. Smiddy WE, Michaels RG, Green WR. Morphology, pathology, and surgery of idiopathic vitreoretinal macular disorders: a review. Retina. 1990;10:288-296.

21. Michaels RG. A clinical and histopathologic study of epiretinal membranes affecting the macula and removed by vitreous surgery. Trans Am Ophthalmol Soc. 1982;80:580-656.

22. Johnson RN, Gass JDM. Idiopathic macular holes: observations, stages of formation, and implications for surgical intervention. Ophthalmology. 1988;95:917-924.

23. Schumann RG, Wolf A, Mayer WJ, et al. Pathology of internal limiting membrane specimens following intravitreal injection of ocriplasmin. Am J Ophthalmol. 2015;160(4):767-778.

24. Johnson MW. Tractional cystoid macular edema: a subtle variant of the vitreomacular traction syndrome. Am J Ophthalmol. 2005;140(2):184. e1-e184.e14.

25. Smiddy WE, Michels RG, Glaser BM, deBustros S. Vitrectomy for macular traction caused by incomplete vitreous separation. Arch Ophthalmol. 1988;106:624-628.

26. Sonmez K, Capone A Jr, Trese MT, Williams GA. Vitreomacular traction syndrome: impact of anatomical configuration on anatomical and visual outcomes. Retina. 2008;28:1207-1214.

27. Lei S, Wenbin W. Vitreomacular traction syndrome [review article]. Chin Med J. 2014;127(8):1566-1571.
28. Yamada N, Kishi S. Tomographic features and surgical outcomes of vitreomacular traction syndrome. Am J Ophthalmol. 2005;139:112-117.

29. Witkin AJ, Patron ME, Castro LC, et al. Anatomic and visual outcomes of vitrectomy for vitreomacular traction syndrome. Ophthalmic Surg Lasers Imaging. 2010;41:425-431.

30. Maumenee IH. Vitreoretinal degenerations as a sign of generalized connective tissue diseases. Am J Ophthalmol. 1979;88:432-449.

31. Snead MP, Yates JRW. Clinical and molecular genetics of Stickler syndrome. Am J Med Genet. 1999;36:353.

32. Duker JS, Kaiser PK, Binder S, et al. The International Vitreomacular Traction Study Group Classification of vitreomacular adhesion, traction, and macular hole. Ophthalmology. 2013;120:2611-2619.

33. Charalampidou S, Nolan J, Beatty S. The natural history of tractional cystoid macular edema. Retina. 2012;32:2045-2051.

34. Margherio RR, Cox MS, Trese MD, Murphy PL, Johnson J, Minor LA. Removal of epimacular membranes. Ophthalmology. 1985;92:1075-1083.

35. Rice TA, de Bustos S, Michaels RG, Thompson JT, Debanne SM, Rowland DY. Prognostic factors in vitrectomy for epiretinal membranes of the macula. Ophthalmology. 1986;93:602-610.

36. McDonald R, Jonhson RN, Schatz H. Surgical results in the vitreomacular traction syndrome. Ophthalmology. 1994;101:1397-1403.

37. Figueroa MS, Contreras I. Vitreomaculopathy surgery. Vitreous. In: Sebag J, editor. Health and Disease. Berlin: Springer Science+Business Media, VA2; 2014:571-600.

38. Kinoshita T, Imaizumi H, Okushiba U, Miyamoto H, Ogino T, Mitamura Y. Time course of changes in metamorphopsia, visual acuity, and OCT parameters after successful epiretinal membrane surgery. Invest Ophthalmol Vis Sci. 2012;53:3592-3597.

39. Shimozono M, Oishi A, Hata M, et al. The significance of cone outer segment tips as a prognostic factor in epiretinal membrane surgery. Am J Ophthalmol. 2012;153:698-704.

40. Suh MH, Seo JM, Park KH, Yu HG. Associations between macular findings by optical coherence tomography and visual outcomes after epiretinal membrane removal. Am J Ophthalmol. 2009;147: 473-480.

41. Falkner-Radler CI, Glittenberg C, Hagen S, Benesch T, Binder S. Spectral-domain optical coherence tomography for monitoring epiretinal membrane surgery. Ophthalmology. 2010;117:798-805.

42. Mitamura Y, Hirano K, Baba T, Yamamoto S. Correlation of visual recovery with presence of photoreceptor inner/outer segment junction in optical coherence images after epiretinal membrane surgery. Br J Ophthalmol. 2009;93:171-175.

43. Chang LK, Fine HF, Spaide RF, Koizumi H, Grossniklaus HE. Ultrastructural correlation of spectral-domain optical coherence tomographic findings in vitreomacular traction syndrome. Am J Ophthalmol. 2008; 146:121-127.

44. Salter AB, Folgar FA, Weissbrot J, Wald KJ. Macular hole surgery prognostic success rates based on macular hole size. Ophthalmic Surg Lasers Imaging. 2012;43:184-189.

45. Lois N, Burr J, Norrie J, et al; Full-thickness Macular Hole and Internal Limiting Membrane Peeling Study (FILMS) Group. Internal limiting membrane peeling versus no peeling for idiopathic full-thickness macular hole: a pragmatic randomized controlled trial. Invest Ophthalmol Vis Sci. 2011;52:1586-1592.

46. Romano MR, Vallejo-Garcia JL, Camesasca FI, Vinciguerra P, Costagliola C. Vitreopapillary adhesion as a prognostic factor in pseudo- and lamellar macular holes. Eye. 2012;26:810-815.

47. Theodossiadis PG, Grigoropoulos VG, Emfietzoglou I, Nikolaidis P, Papathanasiou M, Theodossiadis GP. Spontaneous closure of lamellar macular holes studied by optical coherence tomography. Acta Ophthalmol. 2012;90:96-98.

48. Day S, Martinez JA, Nixon PA, et al. Intravitreal sulfur hexafluoride injection for the treatment of vitreomacular traction syndrome. Retina. Epub Sep 16.

49. Rodrigues IA, Stangos AN, McHugh DA, Jackson TL. Intravitreal injection of expansile perfluoropropane $(\mathrm{c}(3) \mathrm{f}(8))$ for the treatment of vitreomacular traction. Am J Ophthalmol. 2013;155(270-276):e2. 
50. Nasrallah FP, Jalkh AE, Coppenolle FV, et al. The role of the vitreous in diabetic macular edema. Ophthalmology. 1988;95:1335-1339.

51. Jackson TI, Nicod E, Angelis A, et al. Vitreous attachment in age-related macular degeneration, diabetic macular edema, and retinal vein occlusion: a systematic review and meta analysis. Retina. 2013;33:1099-1108.

52. Melberg NS, Williams DF, Balles MW, et al. Vitrectomy for vitreomacular traction syndrome with macular detachment. Retina. 1995;15: 192-197.

53. Avunduk A, Cetinkaya K, Kapicioglu Z, Kaya C. The effect of posterior vitreous detachment on the prognosis of branch retinal vein occlusion. Acta Ophthalmol. 1997;75:441-442.

54. Pakola S, Haller JA. Pharmacologic vitreolysis: clinical trial data. Diseases of the vitreo-macular interface. In: Girach A, de Smet MD, editors. Diseases of the Vitreo-Macular Interface, Essentials in Ophthalmology. Vol. 11. Berlin: Springer; 2014:105-112.

55. Akiba J, Arzabe CW, Trempe CL. Posterior vitreous detachment and neovascularization in diabetic retinopathy. Ophthalmology. 1990;97: 889-891.

56. Krebs I, Brannath W, Glittenberg C, Zeiler F, Sebag J, Binder S. Posterior vitreomacular adhesion: a potential risk factor for exudative age-related macular degeneration? Am J Ophthalmol. 2007;144:741-746.

57. Robison CD, Krebs I, Binder S, et al. Vitreomacular adhesion in active and end-stage age-related macular degeneration. Am J Ophthalmol. 2009;148:79-82.

58. Mojana F, Cheng L, Bartsch DU, et al. The role of abnormal vitreomacular adhesion in age-related macular degeneration: spectral optical coherence tomography and surgical results. Am J Ophthalmol. 2008;146(2):218-227.

59. Stefansson E, Landers MB, Wolbarsht ML. Vitrectomy, lensectomy, and ocular oxygenation. Retina. 1982;2(3):159-166.

60. Gandorfer A. Enzymatic vitreous disruption. Eye. 2008;22: 1273-1277.

61. Gandorfer A. Objective of pharmacologic vitreolysis. Dev Ophthalmol. 2009;44:1-6

62. Gandorfer A. Pharmacologic vitreolysis: rationale, potential indications, and promising agents. Retina. 2012;32(suppl 2):S221-S224.

63. Sebag J, Asari RR, Suh KI. Pharmacologic vitreolysis with microplasmin increases vitreous diffusion coefficients. Graefes Arch Clin Exp Ophthalmol. 2007;245:576-580.

64. Quiram PA, Leverenz VR, Baker RM, Dang L, Giblin FJ, Trese MT. Microplasmin-induced posterior vitreous detachment affects vitreous oxygen levels. Retina. 2007;27:1090-1096.

65. Harooni M, McMillan T, Refojo M. Efficacy and safety of enzymatic posterior vitreous detachment by intravitreal injection of hyaluronidase. Retina. 1998;18:16-22.

66. Gottlieb JL, Antoszyk AN, Hatchell DL, Saloupis P. The safety of intravitreal hyaluronidase. A clinical and histologic study. Invest Ophthalmol Vis Sci. 1990;31:2345-2352.

67. Zhi-Liang W, Wo-Dong S, Min L, Xiao-Ping B, Jin J. Pharmacologic vitreolysis with plasmin and hyaluronidase in diabetic rats. Retina. 2009;29(2):269-274.

68. Staubach F, Nober V, Janknecht P. Enzyme-assisted vitrectomy in enucleated pig eyes: a comparison of hyaluronidase, chondroitinase, and plasmin. Curr Eye Res. 2004;29(4-5):261-268.

69. Bishop PN, McLeod D, Reardon A. Effects of hyaluronan lyase, hyaluronidase, and chondroitin ABC lyase on mammalian vitreous gel. Invest Ophthalmol Vis Sci. 1999;40(10):2173-2178.

70. Kuppermann BD, Thomas EL, de Smet MD, Grillone LR; Vitrase for Vitreous Hemorrhage Study Groups. Vitrase for Vitreous Hemorrhage Study Groups, pooled efficacy results from two multinational randomized controlled clinical trials of a single intravitreous injection of highly purified ovine hyaluronidase (Vitrase) for the management of vitreous hemorrhage. Am J Ophthalmol. 2005;140(4):573-584.

71. Hermel M, Schrage N. Efficacy of plasmin enzymes and chondroitinase $\mathrm{ABC}$ in creating posterior vitreous separation in the pig: a masked, placebo-controlled in vivo study. Graefes Arch Clin Exp Ophthalmol. 2007;3:399-406.
72. Hageman GS, Russell SR. Chondroitinase-mediated disinsertion of the primate vitreous body. Invest Ophthalmol Vis Sci. 1994;35:1260.

73. Tezel TH, Del Priore LV, Kaplan HJ. Posterior vitreous detachment with dispase. Retina. 1998;18:7-15.

74. Jorge R, Oyamaguchi EK, Cardillo JA, Gobbi A, Laicine EM, Haddad A. Intravitreal injection of dispase causes retinal hemorrhages in rabbit and human eyes. Curr Eye Res. 2013;26:107-112.

75. Men G, Peyman GA, Genaidy M, et al. The role of recombinant lysine-plasminogen and recombinant urokinase and sulfur hexafluoride combination in inducing posterior vitreous detachment. Retina. 2004;24(2):199-209.

76. Unal M, Peyman GA. The efficacy of plasminogen-urokinase combination in inducing posterior vitreous detachment. Retina. 2000;20:69-75.

77. O'Neill R, Shea M. The effects of bacterial collagenase in rabbit vitreous. Can J Ophthalmol. 1973;8:366-370.

78. Moorehead LC, Redburn DA, Kirkpatrick DS, Kretzer F. Bacterial collagenase: proposed adjunct to vitrectomy with membranectomy. Arch Ophthalmol. 1980;98:1829-1839.

79. Sebag J. Molecular biology of pharmacologic vitreolysis. Trans Am Ophthalmol Soc. 2005;103:473-494.

80. Moorhead LC, Radtke N. Enzyme-assisted vitrectomy with bacterial collagenase. Pilot human studies. Retina. 1985;5(2):98-100.

81. El Baha SM, Abou-Nazel MW, Idriss HF, Abdel-Megeed AS. The role of streptokinase in induction of posterior vitreous detachment: a scanning and transmission electron microscopic study of the retina in rabbits. Retina. 2003;23(5):698-704.

82. Hesse L, Chofflet J, Kroll P. Tissue plasminogen activator as a biochemical adjuvant in vitrectomy for proliferative vitreoretinopathy. Ger J Ophthalmol. 1995;4:323-327.

83. Hesse L, Nebeling B, Schroeder B, Heller G, Kroll P. Induction of posterior vitreous detachment in rabbits by intravitreal injection of tissue plasminogen activator following cryopexy. Exp Eye Res. 2000; 70(1):31-39.

84. Murakami T, Takagi H, Obashi H, et al. Role of posterior vitreous detachment induced by intravitreal tissue plasminogen activator in macular edema with central retinal artery occlusion. Retina. 2007;27(8): 1031-1037.

85. Tagami M, Kusuhara S, Imai H, Honda S, Tsukahara Y, Negi A. Impact of intravitreal injection of tissue plasminogen activator on full-field electroretinogram in patients with macular oedema secondary to retinal vein occlusion. Ophthalmologica. 2011;226(2):81-86.

86. Le Mer Y, Korobelnik JF, Morel C, Ullern M, Berrod JP. TPA-assisted vitrectomy for proliferative diabetic retinopathy: results of a doublemasked, multicenter trial. Retina. 1999;19:378-382.

87. Yamamoto T, Kamei M, Kunavisarut P, Suzuki M, Tano Y. Increased retinal toxicity of intravitreal tissue plasminogen activator in a central retinal vein occlusion model. Graefes Arch Clin Exp Ophthalmol. 2008;246(4):509-514.

88. Hrach CJ, Johnson MW, Hassan AS, Lei B, Sieving PA, Elner VM. Retinal toxicity of commercial intravitreal tissue plasminogen activator solution in cat eyes. Arch Ophthalmol. 2000;118(5):659-663.

89. Johnson MW, Olsen KR, Hernandez E, Irvine WD, Johnson RN. Retinal toxicity of recombinant tissue plasminogen activator in the rabbit. Arch Ophthalmol. 1990;108(2):259-263.

90. Verstraeten T, Chapman C, Hartzer M, Winkler BS, Trese MT, Williams GA. Pharmacologic induction of PVD in the rabbit. Arch Ophthalmol. 1993;111:849-854.

91. Sakuma T, Tanaka M, Inoue J, Mizota A, Souri M, Ichinose A. Use of autologous plasmin during vitrectomy for diabetic maculopathy. Eur J Ophthalmol. 2006;16:138-140.

92. Sakuma T, Mizota A, Inoue J, Tanaka M. Intravitreal injection of autologous plasmin enzyme for macular edema associated with branch retinal vein occlusion. Am J Ophthalmol. 2010;150(6):876-882.

93. Udaondo P, Diaz-Llopis M, Garcia-Delpech S, Salom D, Romero FJ. Intravitreal plasmin without vitrectomy for macular edema secondary to branch retinal vein occlusion. Arch Ophthalmol. 2011; 129:283-287. 
94. Margherio AR, Margherio RR, Hartzer M, Trese MT, Williams GA, Ferrone PJ. Plasmin enzyme assisted vitrectomy in traumatic pediatric macular holes. Ophthalmology. 1998;105:1617-1620.

95. Wu WC, Drenser KA, Trese MT, Williams GA, Capone A. Pediatric traumatic macular hole: results of autologous plasmin enzyme-assisted vitrectomy. Am J Ophthalmol. 2007;144:668-672.

96. Hikichi T, Yanagiya N, Kado M, Akiba J, Yoshida A. Posterior vitreous detachment induced by injection of plasmin and sulfur hexafluoride in the rabbit vitreous. Retina. 1999;19:55-58.

97. Gandorfer A, Putz E, Welge-Lussen U, Grüterich M, Ulbig M, Kampik A. Ultrastructure of the vitreoretinal interface following plasmin assisted vitrectomy. Br J Ophthalmol. 2001;85:6-10.

98. Williams JG, Trese MT, Williams GA, Hartzer MK. Autologous plasmin enzyme in the surgical management of diabetic retinopathy. Ophthalmology. 2001;108:1902-1905.

99. Li X, Shi X, Fan J. Posterior vitreous detachment with plasmin in the isolated human eye. Graefes Arch Clin Exp Ophthalmol. 2002; 240:56-62.

100. Chow DR, Williams GA, Trese MT, Margherio RR, Ruby AJ, Ferrone PJ. Successful closure of traumatic macular holes. Retina. 1999; 19:405-409.

101. Trese MT, Williams GA, Hartzer MK. A new approach to stage 3 macular holes. Ophthalmology. 2000;107:1607-1611.

102. Maier M, Feucht N, Burzer S, Lohmann CP. Vitreomakuläres Traktionssyndrom [Vitreomacular Traction Syndrome]. Klin Monatsbl Augenheilkd. 2013;230:920-928. German.

103. Shah AR, Trese MT. Enzymatic vitrectomy and pharmacologic vitreodynamics. Dev Ophthalmol. 2016;55:357-364.

104. Willekens K, Abegão Pinto L, Vandewalle E, Stalmans I, Stalmans P. Improved efficacy of ocriplasmin for vitreomacular traction release and transient changes in optic disk morphology. Retina. 2015; 35(6):1135-1143.

105. Gandorfer A, Rohleder M, Sethi C, et al. Posterior vitreous detachment induced by microplasmin. Invest Ophthalmol Vis Sci. 2004; 45:641-647.

106. Maier M, Abraham S, Frank C, Feucht N, Lohmann CP. Ocriplasmin as a treatment option for symptomatic vitreomacular traction with and without macular hole: first clinical experiences. Ophthalmologe. 2015;112(12):990-994.

107. Sharma P, Juhn A, Houston SK, et al. Efficacy of intravitreal ocriplasmin on vitreomacular traction and full-thickness macular holes. $\mathrm{Am}$ J Ophthalmol. 2015;159(5):861.e-867.e.

108. de Smet MD, Gandorfer A, Stalmans P, et al. Microplasmin intravitreal administration in patients with vitreomacular traction scheduled for vitrectomy: the MIVI I trial. Ophthalmology. 2009;116: 1349-1355.

109. Stalmans P, Delaey C, de Smet MD, van Dijkman E, Pakola S. Intravitreal injection of microplasmin for treatment of vitreomacular adhesion: results of a prospective, randomized, sham-controlled phase II trial (the MIVI-IIT trial). Retina. 2010;30:1122-1127.

110. Haller JA, Stalmans P, Benz MS, et al; MIVI-TRUST Study Group. Efficacy of intravitreal ocriplasmin for treatment of vitreomacular adhesion: subgroup analyses from two randomized trials. Ophthalmology. 2015;122(1):117-122.

111. Abou Ltaif S, Herbert L. Delayed full-thickness macular hole closure without vitreomacular traction release following ocriplasmin injection. BMJ Case Rep. 2015:1-3.

112. Novack RL, Staurenghi G, Girach A, Narendran N, Tolentino M. Safety of intravitreal ocriplasmin for focal vitreomacular adhesion in patients with exudative age-related macular degeneration. Ophthalmology. 2015;122(4):796-802.

113. Steel DH, Sandinha MT, White K. The plane of vitreoretinal separation and results of vitrectomy surgery in patients given ocriplasmin for idiopathic macular hole. Invest Ophthalmol Vis Sci. 2015; 56(6):4038-4044.
114. Jeng KW, Baumal CR, Witkin AJ, Witkin SR, Wiegand TW, Waheed NK. Incomplete release of vitreomacular attachments after intravitreal ocriplasmin. Ophthalmic Surg Lasers Imaging Retina. 2015;46(2):271-274.

115. Stalmans P, Benz MS, Gandorfer A, et al; MIVI-TRUST Study Group. Enzymatic vitreolysis with ocriplasmin for vitreomacular traction and macular holes. N Engl J Med. 2012;367:606-615.

116. Rossi S, Orrico A, Melillo P, Testa F, Simonelli F, Della Corte M. Ocriplasmin use in a selected case with preserved visual acuity. BMC Ophthalmol. 2015;15:146.

117. Dugel PU, Regillo C, Eliott D. Characterization of anatomic and visual function outcomes in patients with full-thickness macular hole in ocriplasmin phase 3 trials. Am J Ophthalmol. 2015; 160(1):94.e-99.e.

118. Modi YS, Singh RP. Ocriplasmin-induced macular hole closure in the absence of vitreomacular adhesion release. Ophthalmic Surg Lasers Imaging Retina. 2015;46(6):677-679.

119. Beebe DB. Understanding the adverse effects of ocriplasmin: comments and response. JAMA Ophthalmol. 2015;133:229-230.

120. Chatziralli I, Theodossiadis G, Parikakis E, Datseris I, Theodossiadis P. Real-life experience after intravitreal ocriplasmin for vitreomacular traction and macular hole: a spectral-domain optical coherence tomography prospective study. Graefes Arch Clin Exp Ophthalmol. Epub 2015 May 5.

121. Gandorfer A, Benz MS, Haller JA, et al; MIVI-TRUST Study Group. Association between anatomical resolution and functional outcomes in the mivi-trust studies using ocriplasmin to treat symptomatic vitreomacular adhesion/vitreomacular traction, including when associated with macular hole. Retina. 2015;35(6):1151-1157.

122. Mangione CM, Lee PP, Gutierrez PR, et al; National Eye Institute Visual Function Questionnaire Field Test Investigators. Development of the 25-list-item National Eye Institute Visual Function Questionnaire: epidemiology and biostatistics. Arch Ophthalmol. 2001;119(7):1050-1058.

123. Fahim AT, Khan NW, Johnson MW. Acute panretinal structural and functional abnormalities after intravitreous ocriplasmin injection. JAMA Ophthalmol. 2014;132(4):484-486.

124. Keller J, Haynes RJ. Zonular dehiscence at the time of combined vitrectomy and cataract surgery after intravitreal ocriplasmin injection. JAMA Ophthalmol. 2015;133(9):1091-1092.

125. Kim JE. Safety and complications of ocriplasmin ocriplasmin, ocriplasmin; oh, how safe art thou? JAMA Ophthalmol. 2014; 132(4):379-380.

126. Hahn P, Chung MM, Flynn HW Jr, et al. Safety profile of ocriplasmin for symptomatic vitreomacular adhesion: a comprehensive analysis of premarketing and postmarketing experiences. Retina. 2015;35(6):1128-1134.

127. Kaiser PK, Kampik A, Kuppermann BD, Girach A, Rizzo S, Sergott RC. Safety profile of ocriplasmin for the pharmacologic treatment of symptomatic vitreomacular adhesion/traction. Retina. 2015; 35(6):1111-1127.

128. Han IC, Scott AW. Sterile endophthalmitis after intravitreal ocriplasmin injection: report of a single case. Retin Cases Brief Rep. 2015;9(3):242-244.

129. Johnson MW, Fahim AT, Rao RC. Acute ocriplasmin retinopathy. Retina. 2015;35(6):1055-1058.

130. Gómez-Ulla F, Bande MF, Abraldes M. Acute loss of vision after an intravitreal injection ocriplasmin: a functional evolutionary study for 1-year follow-up. Doc Ophthalmol. 2015;131(3):231-235.

131. Nudleman E, Franklin MS, Wolfe JD, Williams GA, Ruby AJ. Resolution of subretinal fluid and outer retinal changes in patients treated with ocriplasmin. Retina. Epub 2015 Sep 21:1-6.

132. Quezada-Ruiz C, Pieramici DJ, Nasir M, et al. Outer retina reflectivity changes on SD-OCT after intravitreal ocriplasmin for vitreomacular traction and macular hole. Retina. 2015;35(6):1144-1150. 
133. Small KW, Shaya FS, La Fontaine M. Post-market experience with ocriplasmin including chronic electrophysiologic changes. Ophthalmic Surg Lasers Imaging Retina. 2015;46(9):956-962.

134. Wong SC, Capone A Jr. Microplasmin (ocriplasmin) in pediatric vitreoretinal surgery update and review. Retina. 2013;33:339-348.

135. Freund KB, Shah SA, Shah VP. Correlation of transient vision loss with outer retinal disruption following intravitreal ocriplasmin. Eye (Lond). 2013;27(6):773-774.

136. Tibbetts MD, Reichel E, Witkin AJ. Vision loss after intravitreal ocriplasmin: correlation of spectral-domain optical coherence tomography and electroretinography. JAMA Ophthalmol. 2014; 132(4):487-490.

137. Abraham S, Wand K, Stumpfe S, Feucht N, Lohmann CP, Maier M. Unklare Retinopathie nach intravitrealer Eingabe von Ocriplasmin [Unclear retinopathy after intravitreal injection of ocriplasmin]. Ophthalmologe. Epub 2015 Jul 24. [German].

138. Barteselli G, Carini E, Invernizzi A, Ratiglia R, Viola F. Early panretinal abnormalities on fundus autofluorescence and spectral domain optical coherence tomography after intravitreal ocriplasmin. Letter to the Editor. Acta Ophthalmol. 2015:1-2.

139. Hager A, Seibel I, Riechardt A, Rehak M, Joussen AM. Does ocriplasmin affect the RPE - photoreceptor adhesion in macular holes? Br J Ophthalmol. 2015;99:635-638.

140. Hale BP, Au AK, Falk NS, Bhatnagar P, Beer PM. Flat electroretinography and acute visual loss after ocriplasmin injection for vitreomacular adhesion complicating macular schisis. Ophthalmic Surg Lasers Imaging Retina. 2015;46(8):888-892.

141. Luttrull JK. Chronic serous macular detachments and visual disturbance complicating consecutive cases of symptomatic vitreomacular adhesion with macular hole treated with ocriplasmin. Ophthalmic Surg Lasers Imaging. 2015;46(9):976-978.

142. European Medicines Agency [webpage on the Internet]. Ocriplasmin Assessment Report. Available from: http://www.ema.europa.eu/ docs/en_GB/document_library/EPAR_-_Public_assessment_report/ human/002381/WC500142228.pdf. Accessed November 24, 2015.

143. Sakuma T, Tanaka M, Mizota A, Inoue J, Pakola S. Safety of in vivo pharmacologic vitreolysis with recombinant microplasmin in rabbit eyes. Invest Ophthalmol Vis Sci. 2005;46:3295-3299.

144. Lee GD, Taney LS, Rogers AH, Shah CP, Duker JS, Baumal CR. Surgical outcomes for persistent macular hole after ocriplasmin. Ophthalmic Surg Lasers Imaging. 2015;46(7):732-736.

145. Chatziralli IP, Theodossiadis GP, Parikakis E, Datseris I, Theodossiadis P. Complications of intravitreal ocriplasmin for vitreomacular traction and macular hole: a prospective spectral-domain optical coherence tomography study. Cutan Ocul Toxicol. Epub 2015 Nov 10.

146. Casswell E, Fernandez-Sanz G, Mitry D, Luk S, Zakir R. Macular hole progression following ocriplasmin intravitreal injection. Case Rep Ophthalmol Med. 2014;2014:403461.

147. Chod RB, Goodrich C, Saxena S, Akduman L. Lamellar macular hole after intravitreal ocriplasmin injection. BMJ Case Rep. 2015.

148. Khan MA, Shahlaee A, Ho AC. Reopening of a full-thickness macular hole 2 years after pharmacologic closure with ocriplasmin. JAMA Ophthalmol. 2015;133(11):1362-1364.

149. Alberti M, la Cour M. Is visual acuity non-inferior in full-thickness macular holes treated with ocriplasmin?, Letter to the Editor. Acta Ophthalmol. Epub 2015 Sep 26.

Clinical Ophthalmology

\section{Publish your work in this journal}

Clinical Ophthalmology is an international, peer-reviewed journal covering all subspecialties within ophthalmology. Key topics include: Optometry; Visual science; Pharmacology and drug therapy in eye diseases; Basic Sciences; Primary and Secondary eye care; Patien Safety and Quality of Care Improvements. This journal is indexed on Submit your manuscript here: http://www.dovepress.com/clinical-ophthalmology-journal
150. Johnson MW, Fahim AT. Letters: comment \& response: understanding the adverse effects of ocriplasmin. JAMA Ophthalmol. 2014;4:E1.

151. Khan MA, Haller JA. Clinical management of vitreomacular traction. Curr Opin Ophthalmol. 2015;26(3):143-148.

152. Christoforidis JB, D’Amico DJ. Surgical and other treatments of diabetic macular edema: an update. Int Ophthalmol Clin. 2004; 44(1):139-160.

153. Lewis H, Abrams GW, Blumenkranz MS, Campo RV. Traction and edema associated with posterior hyaloidal traction. Ophthalmology. 1992;99:753-759.

154. ClinicalTrials [homepage on the Internet]. Diabetic Macular Edema [MIVI-II-DME (TG-MV-002)]. Available from: http:// www.ClinicalTrials.gov. Accessed November 24, 2015. [Study ID: NCT00412451].

155. Patel A, Morse L. Ocriplasmin for foveal schisis in X-linked retinoschisis. Retin Cases Brief Rep. 2015;9(3):248-251.

156. Khoshnevis M, Sebag J. Pharmacologic vitreolysis with ocriplasmin: rationale for use and therapeutic potential in vitreo-retinal disorders BioDrugs. 2015;29(2):103-112.

157. ThromboGenics [webpage on the Internet]. Ocriplasmin Research to Better Inform Treatment (ORBIT). Available from: https://clinicaltrials.gov/ct2/show/NCT02079883. Accessed November 24, 2015. [NLM identifier: NCT02079883].

158. ThromboGenics [webpage on the Internet]. A Retrospective Chart Review of Patients Treated with Ocriplasmin for Symptomatic VMA (OZONE). Available from: https://clinicaltrials.gov/ct2/show/study/ NCT02193945. Accessed December 11, 2015. [NLM identifier: NCT02193945].

159. ThromboGenics [webpage on the Internet]. Ocriplasmin for Treatment for Symptomatic Vitreomacular Adhesion Including Macular Hole (OASIS). Available from: https://clinicaltrials.gov/ct2/show/record/ NCT01429441?term=OASIS+OCRIPLASMIN\&rank=1. Accessed December 11, 2015.

160. Tolentino M. Long-term clinical outcomes with ocriplasmin: The OASIS Study - baseline demographics and ocular characteristics. Poster presented at: Association for Research in Vision and Ophthalmology Annual Meeting; May 4, 2014; Orlando, FL.

161. Wang Z-L, Zhang X, Xu X, Sun XD, Wang F. PVD following plasmin but not hyaluronidase: implications for combination pharmacologic vitreolysis therapy. Retina. 2005;25(1):38-43.

162. Quiroz-Mercado H. Update on integrin antagonists. Conference presented at: American Academy of Ophthalmology Meeting: Subspecialty Day Retina. Section VIII: Neovascular AMD; October 17, 2014; Chicago, IL

163. Allegroeye.org [homepage on the Internet]. Allegro Ophthalmic LCC. Allegro Ophthalmic Announces Positive Topline Results from Phase 2 Trial Evaluating Luminate in Patients with Vitreomacular Traction or Vitreomacular adhesion [updated July 13, 2015; October 1, 2015]. Available from: www.allegroeye.com/press-release. Accessed October 1, 2015.

164. Boyer DS [webpage on the Internet]. Integrin Blockade as a Retinovascular Therapy. Allegroeye uploads [article on the Internet]; 2014 [cited January 31, 2014]. Available from: www.allegroeye.com/?s=uploads. Accessed October 1, 2015

PubMed Central and CAS, and is the official journal of The Society of Clinical Ophthalmology (SCO). The manuscript management system is completely online and includes a very quick and fair peer-review system, which is all easy to use. Visit http://www.dovepress.com/ testimonials.php to read real quotes from published authors. 